\title{
Bipolar Membrane Electrodialysis for Ammonia Recovery from Synthetic Urine: Experiments, Modeling, and Performance Analysis
}

\author{
Yujiao Li, ${ }^{\nabla}$ Ruoyu Wang, ${ }^{\nabla}$ Shaoyuan Shi, Hongbin Cao, Ngai Yin Yip, and Shihong Lin*
}

Cite This: Environ. Sci. Technol. 2021, 55, 14886-14896

Read Online

ABSTRACT: Recovering nitrogen from source-separated urine is an important part of the sustainable nitrogen management. A novel bipolar membrane electrodialysis with membrane contactor (BMED-MC) process is demonstrated here for efficient recovery of ammonia from synthetic source-separated urine $\left(\sim 3772 \mathrm{mg} \mathrm{N} \mathrm{L}^{-1}\right)$. In a BMED-MC process, electrically driven water dissociation in a bipolar membrane simultaneously increases the $\mathrm{pH}$ of the urine stream and produces an acid stream for ammonia stripping. With the increased $\mathrm{pH}$ of urine, ammonia transports across the gas-permeable membrane in the membrane contactor and is recovered by the acid stream as ammonium sulfate that can be directly used as fertilizer. Our results obtained using batch experiments demonstrate that the BMED-MC process can achieve $90 \%$ recovery. The average ammonia flux and the specific energy consumption can be regulated by varying the current density. At a current density of $20 \mathrm{~mA} \mathrm{~cm}{ }^{-2}$, the energy required to

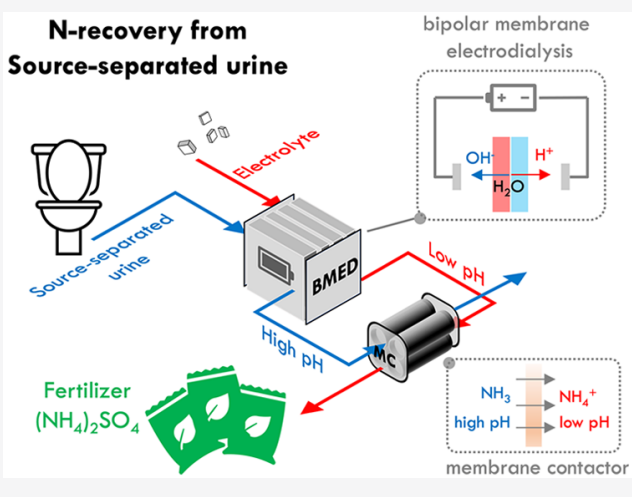
achieve a $67.5 \%$ ammonia recovery in a $7 \mathrm{~h}$ batch mode is $92.8 \mathrm{MJ} \mathrm{kg}^{-1} \mathrm{~N}$ for a bench-scale system with one membrane stack and can approach $25.8 \mathrm{MJ} \mathrm{kg}^{-1} \mathrm{~N}$ for large-scale systems with multiple membrane stacks, with an average ammonia flux of $2.2 \mathrm{~mol} \mathrm{~m}{ }^{-2}$ $\mathrm{h}^{-1}$. Modeling results show that a continuous BMED-MC process can achieve a $90 \%$ ammonia recovery with a lower energy consumption (i.e., $12.5 \mathrm{MJ} \mathrm{kg}^{-1} \mathrm{~N}$ ). BMED-MC shows significant potential for ammonia recovery from source-separated urine as it is relatively energy-efficient and requires no external acid solution.

KEYWORDS: nutrient recovery, bipolar membrane electrodialysis, membrane contactor, source-separated urine, performance analysis

\section{INTRODUCTION}

Nitrogen is an essential nutrient to life and its bioavailable form, ammonium nitrogen, has been utilized to increase agricultural production for the growing global population. ${ }^{1,2}$ To produce ammonium nitrogen for fertilization, the HaberBosch process has been applied since the beginning of the 20th century for nitrogen fixation from the atmosphere. ${ }^{3}$ However, this process is energy-intensive with a significant carbon footprint. Meanwhile, anthropogenic discharge of bioavailable nitrogen via wastewater causes eutrophication. ${ }^{4}$ Nitrificationdenitrification and other deammonification processes are typically adopted in conventional wastewater treatment plants for nitrogen removal where nitrogen is released back to the atmosphere as nitrogen gas. ${ }^{5,6}$ The nitrogen cycle would be more sustainable if nitrogen in waste streams can be recovered for agricultural production to reduce the demand for ammonia production from the energy-intensive Haber-Bosch process. ${ }^{7,8}$

As urine contributes to nearly $80 \%$ wastewater nitrogen, recovering nitrogen from source-separated urine can be a promising approach for sustainable nitrogen management, especially considering the higher nitrogen content in undiluted source-separated urine. 9,10 Various approaches have been proposed to recover ammonia from urine or wastewater. ${ }^{11-19}$ Promising methods include isothermal membrane distillation with acidic collector (IMD-AC), electrochemical cell with membrane stripping, and flow-electrode capacitive deionization with membrane stripping. ${ }^{16-19}$ Similar to membrane contactor, IMD-AC recovers ammonia from urine via membrane distillation where the isothermal condition hinders the undesired water transport and thus improves selectivity for ammonia flux as compared to conventional membrane distillation. ${ }^{16}$ The use of acidic stripping solution can further increase ammonia flux. Electrochemical stripping integrates an acid trap chamber next to the cathode chamber of an electrochemical cell separated by a gas-permeable membrane. The $\mathrm{pH}$ of urine increases in the cathode chamber under applied voltage without chemical addition, and ammonia is recovered by the adjacent acid trap chamber. ${ }^{17}$ Membrane stripping can also be separated from the electrochemical cell. $^{11,18,20}$

Received: August 7, 2021

Revised: September 22, 2021

Accepted: September 23, 2021

Published: October 12, 2021

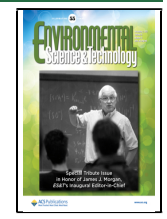


(A)

$$
\text { Batch (one unit) }
$$

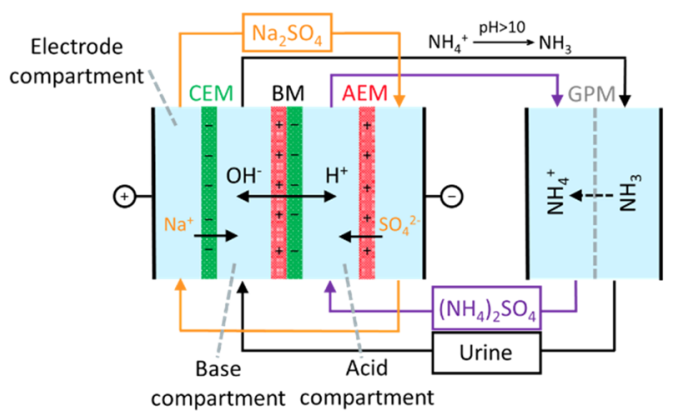

(B)

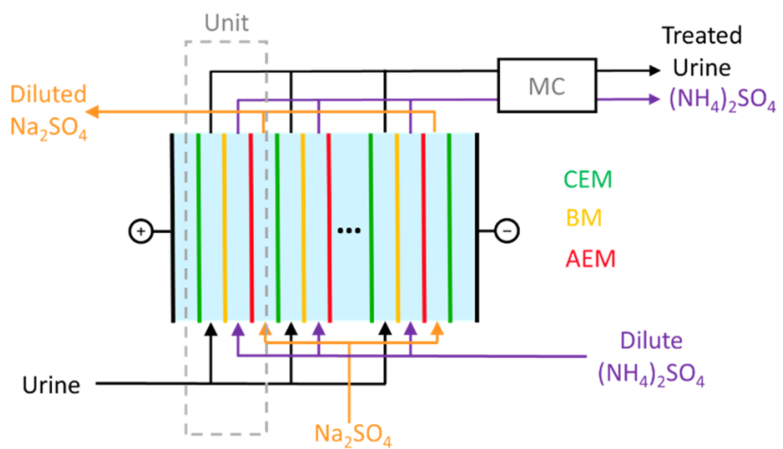

Figure 1. (A) Schematic diagram of a batch BMED-MC system with one repeating unit in the BMED stack. The BMED cell on the left consists of a base compartment (between CEM and BM), an acid compartment (between AEM and BM), and electrode compartments. The MC cell consists of two compartments separated by a gas-permeable membrane (i.e., a PVDF membrane in this study), with the left compartment connecting to the acid compartment of the BMED cell and the right compartment connecting to the base compartment of the BMED cell. (B) Schematic diagram of a continuous BMED-MC system with multiple repeating units in the BMED stack. A repeating unit is labeled out by a dashed rectangle. All streams flow through the BMED cell with single pass. Electrode stream is recirculated and not plotted for simplification.

Other variants of electrochemical stripping include the $\mathrm{H}_{2}$ recycling electrochemical system where $\mathrm{H}_{2}$ produced at the cathode is recycled to the anode to reduce energy input ${ }^{21,22}$ and gas-diffusion-electrode-based system in which ammonia is stripped by airflow immediately after being produced in the cathode to mitigate ammonia back-diffusion. ${ }^{23}$ Capacitive membrane stripping integrates a capacitive deionization process with a membrane contactor for ammonia recovery. Ammonia selectively accumulates in the flowing cathode followed by a stripping step within the membrane contactor where ammonium sulfate is produced. ${ }^{19}$ However, all of these processes still require a continuous external acid or buffer input for efficient recovery of ammonia from urine. Another newly developed electrochemical approach to selectively remove ammonium from wastewater is battery deionization where copper hexacyanoferrate battery electrodes can concentrate ammonium via intercalation under low voltage. However, additional separation steps for ammonia recovery are still required. $^{24-26}$

Bipolar membrane electrodialysis with membrane contactor (BMED-MC) process is a promising approach to recover ammonia nitrogen from urine as fertilizer. ${ }^{27-29}$ Bipolar membrane electrodialysis (BMED) is a relatively novel electrodialysis process that leverages water dissociation within a bipolar membrane, instead of electrolysis, for the simultaneous production of acid and base. ${ }^{30,31}$ BMED has been applied as a $\mathrm{pH}$ adjustment process where precise control of $\mathrm{pH}$ can be achieved by varying the current density and hydraulic retention time. ${ }^{32-34}$ As ammonia is a weak base, the dissociation equilibrium between ammonia $\left(\mathrm{NH}_{3}\right)$ and ammonium $\left(\mathrm{NH}_{4}^{+}\right)$is strongly affected by the solution $\mathrm{pH}$. BMED can be used to increase the $\mathrm{pH}$ of urine and simultaneously produce an acid stream (i.e., the stripping stream) for ammonia recovery without any external acid and base consumption.

In previous studies using BMED for ammonia recovery, urine was fed into the BMED system to produce concentrated dissolved ammonia for further stripping. ${ }^{27,28}$ Recently, a minimal bipolar membrane cell configuration was proposed for ammonia recovery where the anion-exchange membrane is not used in the cell pairs compared to a regular BMED configuration. In this configuration, ammonium first competitively transports across cation-exchange membranes against other cations from acidic compartment to basic compartment, thereby becoming concentrated and converted to ammonia. An external acid stream is then used to strip and recover ammonia. It was reported that ammonia recovery using this configuration only consumes $18.3 \mathrm{MJ} \mathrm{kg}^{-1} \mathrm{~N}$ when treating $\sim 2$ $\mathrm{g} \mathrm{N} \mathrm{L}^{-1}$ synthetic wastewater. ${ }^{29}$ However, $3 \mathrm{M}$ of acid solution was supplied as the stripping solution.

In this study, we demonstrate a novel process coupling bipolar membrane electrodialysis with membrane contactor (BMED-MC) to recover ammonia from ammonium solutions and synthetic urine. In such a process, BMED is used both to adjust the $\mathrm{pH}$ of the source-separated urine for converting ammonium to ammonia and to produce the acid that is needed for ammonia stripping via a membrane contactor. A membrane contactor (MC) utilizes a porous hydrophobic membrane to separate two streams and facilitates mass transfer across the membrane along the chemical potential gradient ${ }^{35}$ and can thus be used to recover ammonia vapor from the basic urine stream into the acid stream. ${ }^{36,37}$ We first present the working principle and model framework of BMED-MC and test the BMED-MC process using synthetic urine that mimics the composition of real urine (containing representative species other than $\mathrm{NH}_{3} / \mathrm{NH}_{4}^{+}$). We then characterize the process kinetics by evaluating the effects of current density on the average ammonia flux and recovery. We also quantify the energy consumption of both batch and continuous BMEDMC processes and compare them with other ammonia recovery approaches. Finally, we discuss the implications of BMED-MC for ammonia recovery from source-separated urine and other possible applications.

\section{MATERIALS AND METHODS}

Working Principles and System Setup. BMED is a special variant of regular electrodialysis where a bipolar membrane $(\mathrm{BM})$ is inserted between each pair of cationexchange membrane (CEM) and anion-exchange membrane (AEM) to form a CEM/BM/AEM assembly. ${ }^{38,39}$ Electrical current is sustained by the coupled phenomena of ion transport across the ion-exchange membranes (IEMs) and water dissociation across the bipolar membranes. A simplest repeating unit of BMED consists of a CEM, a BM, an AEM, and three compartments separated by each pair of membranes (Figure 1). The compartment sandwiched between CEM and 
BM produces a base stream as hydroxide ions $\left(\mathrm{OH}^{-}\right)$form at $\mathrm{BM}$ and pair with cations (e.g., $\mathrm{Na}^{+}$) transporting across CEM. The compartment sandwiched between BM and AEM produces an acid stream as hydrogen ions $\left(\mathrm{H}^{+}\right)$form at $\mathrm{BM}$ and pair with anions (e.g., $\mathrm{SO}_{4}{ }^{2-}$ ) transporting across AEM. The compartment sandwiched between AEM and CEM (of next repeating unit) produces a desalinated salt stream as cations and anions transported to adjacent compartments to form base and acid, respectively.

In the proposed BMED-MC process, the urine feed stream first flows through the base compartments of BMED. As a result, $\mathrm{pH}$ of the urine stream increases, which promotes ammonium nitrogen conversion to ammonia nitrogen. Meanwhile, an acid stream (e.g., sulfuric acid) is produced in the acid compartments for stripping ammonia evaporating from the urine stream. The acid stream and the urine stream with high ammonia concentration then flow through the MC cell. The two liquid streams are separated by a porous hydrophobic gas-permeable membrane (GPM) in the MC cell. As ammonia is volatile, the transmembrane difference of ammonia vapor pressure drives ammonia to diffuse through the membrane from the urine stream to the acid stream. Other nonvolatile components cannot permeate across the membrane and thus remain in the urine stream.

Up to this point, the BMED-MC process separates ammonia from urine and recovers it as a valuable product, e.g., ammonium sulfate. The BMED-MC process can be operated in either batch mode (Figure 1A) or continuous mode (Figure 1B). In the continuous mode, the ammonia recovery is achieved with a single pass of urine through $\mathrm{BMED}$ and MC cells. Steady-state operation can be achieved in the continuous mode where the effluent ammonia concentration and recovery are constant over time, while, in the batch mode, the urine and acid streams coming out of the MC will flow back to the inlets of the BMED cell to form two circulated loops (Figure 1A). Ammonia concentration in the urine stream decreases while more ammonia is recovered over time if no new feed urine stream is introduced to the system. We note when the BMED cell contains only one repeating unit, the electrode compartment also functions as the salt compartment where electrode solution is desalinated. When multiple repeating units are stacked, an additional salt stream is required to flow through the salt compartments between AEMs and CEMs. ${ }^{40,41}$

In this study, the experiments were performed in the batch mode using a custom-built BMED cell connected to an MC cell (Figure S1). The BMED cell consists of a rutheniumcoated titanium anode, a stainless steel cathode, an AEM (Neosepta AMX, ASTOM Co., Japan), a CEM (Neosepta CMX, ASTOM Co., Japan), a BM (Neosepta BP-1, Tokuyama Co., Japan; $I-V$ curve under experimental conditions is provided in Figure S2) and spacers. These components were assembled to create the simplest repeating unit of BMED, where the electrode compartments also function as the salt compartments (Figure 1A). Each membrane has an effective area of $50 \mathrm{~cm}^{2}$. The base and acid compartments have a thickness of $1 \mathrm{~mm}$ and are filled with spacers. The base and acid compartments were connected to the MC cell to form a base loop and an acid loop.

A hydrophobic poly(vinylidene fluoride) (PVDF) membrane $(0.45 \mu \mathrm{m}$ pore size, GE Healthcare) with an effective membrane area of $60 \mathrm{~cm}^{2}$ was used in the MC cell. The base loop was initially circulated with $500 \mathrm{~mL}$ of synthetic urine, simplified urine, or ammonium solution (Table S1), and the acid loop was initially circulated with $200 \mathrm{~mL}$ of $0.01 \mathrm{~mol} \mathrm{~L}^{-1}$ $\left(\mathrm{NH}_{4}\right)_{2} \mathrm{SO}_{4}$ solution. Electrode compartments have a thickness of $6 \mathrm{~mm}$ and were circulated with $1 \mathrm{~L}$ of $0.4 \mathrm{~mol} \mathrm{~L}^{-1} \mathrm{Na}_{2} \mathrm{SO}_{4}$ solution. All streams were circulated through the corresponding compartments using peristaltic pumps (Fisher Scientific) at a flow rate of $100 \mathrm{~mL} \mathrm{~min}^{-1}$. A regulated direct current power supply (Lavolta BPS-305) was used to apply a constant current across the BMED cell. All experiments were conducted without active temperature control.

Experimental Design and Performance Assessment. To demonstrate the potential of BMED-MC for high recovery of ammonia from urine, an experiment was first conducted at a constant current density of $60 \mathrm{~mA} \mathrm{~cm}{ }^{-2}$ for $12 \mathrm{~h}$. A synthetic urine solution, a simplified urine, and an ammonium solution (Table S1) were tested as the feed solution in the base loop. All feed solutions have a similar $\mathrm{pH}$ (i.e., 8.0-9.0) and total ammonia nitrogen (TAN) concentration (i.e., 3360-3772 mg $\mathrm{N} \mathrm{L}^{-1}$ ). TAN concentrations in the base and acid streams were measured every hour using spectrophotometry method with Nessler's reagent. ${ }^{42}$ Additionally, the $\mathrm{pH}$ of the base and acid streams was monitored over time with a $\mathrm{pH}$ meter (Oakton $\mathrm{pH} 700$ ). The applied current on the BMED cell was cut off when the $\mathrm{pH}$ of the base stream exceeded 12.0. Ammonia recovery, $R$ (\%), was calculated by dividing the TAN mass increase in the acid stream by the initial TAN mass in the base stream (eq 1)

$$
R(\%)=\frac{\left(c_{\mathrm{TAN}}^{\mathrm{a}}(t)-c_{\mathrm{TAN}}^{\mathrm{a}}(0)\right) V_{\mathrm{a}}}{c_{\mathrm{TAN}}^{\mathrm{b}}(0) V_{\mathrm{b}}} \times 100 \%
$$

where $V_{\mathrm{a}}$ and $V_{\mathrm{b}}$ are the volumes (L) of acid and base solutions, respectively; $c_{\text {TAN }}^{\mathrm{a}}(0)$ and $c_{\text {TAN }}^{\mathrm{b}}(0)$ are the initial TAN concentrations $\left(\mathrm{mol} \mathrm{L}^{-1}\right)$ in the acid and base streams, respectively; and $c_{\text {TAN }}^{\mathrm{a}}(t)$ is the TAN concentration $\left(\mathrm{mol} \mathrm{L}^{-1}\right)$ in the acid stream at operation time $t$.

To investigate the effect of current density on ammonia recovery performance and evaluate process energy consumption, BMED-MC experiments were performed with different current densities $\left(10,20,40\right.$, and $\left.60 \mathrm{~mA} \mathrm{~cm}^{-2}\right)$ with the synthetic urine (Table S1). In all experiments, the applied current was cut off when the $\mathrm{pH}$ of the base stream exceeded 12.0. The average ammonia flux $\left(\bar{J}_{\mathrm{NH}_{3}}(t), \mathrm{mol} \mathrm{m}^{-2} \mathrm{~h}^{-1}\right)$ within the operation duration $t(\mathrm{~h})$ was calculated by dividing the TAN mass increase in the acid stream over the effective membrane area $\left(\mathrm{m}^{2}\right)$ of the $\mathrm{MC}$ cell, $A_{\mathrm{MC}}$, and duration $t$ (eq 2)

$$
\bar{J}_{\mathrm{NH}_{3}}(t)=\frac{\left(c_{\mathrm{TAN}}^{\mathrm{a}}(t)-c_{\mathrm{TAN}}^{\mathrm{a}}(0)\right) V_{\mathrm{a}}}{A_{\mathrm{MC}} t}
$$

The dissociation equilibrium between ammonia $\left(\mathrm{NH}_{3}\right)$ and ammonium $\left(\mathrm{NH}_{4}^{+}\right)$over time in each stream was evaluated by estimating the concentration ratio of ammonia nitrogen over TAN, $\alpha(t)$, which is a function of $\mathrm{pH}$ and equilibrium constant $K_{\mathrm{a}}$ (eq 3)

$$
\alpha(t)=\frac{c_{\mathrm{NH}_{3}}(t)}{c_{\mathrm{TAN}}(t)}=\frac{K_{\mathrm{a}}}{K_{\mathrm{a}}+10^{-\mathrm{pH}(t)}}
$$

The specific energy consumption (SEC, $\mathrm{kJ} \mathrm{kg}^{-1} \mathrm{~N}$ ) of the BMED-MC process, defined as the energy consumed to recover a unit mass of nitrogen, is calculated with experimentally recorded cell voltage data, $U(t)$, under different 
current densities (eq 4). The energy consumption for stream circulation is assumed to be minor and thus not included for analysis

$$
\mathrm{SEC}=\frac{i A_{\mathrm{ED}} \int_{0}^{t} U(t) \mathrm{d} t}{\left(c_{\mathrm{TAN}}^{\mathrm{a}}(t)-c_{\mathrm{TAN}}^{\mathrm{a}}(0)\right) V_{\mathrm{a}} M_{\mathrm{N}}}
$$

where $i$ is the applied current density $\left(\mathrm{A} \mathrm{m} \mathrm{m}^{-2}\right), A_{\mathrm{ED}}$ is the effective membrane area $\left(\mathrm{m}^{2}\right)$ in the BMED cell, $t$ is the BMED cell operation duration ( $\mathrm{s}$ ), and $M_{\mathrm{N}}$ is the molar mass $\left(\mathrm{g} \mathrm{mol}^{-1}\right)$ of nitrogen. Considering the practical application of the BMED-MC process, where the full-scale system will have hundreds of repeating units in the BMED stack (Figure 1B), the energy consumption will be mainly attributed to the repeating cell units and the energy consumption attributed to the terminal electrodes is negligible to the full-stack energy consumption. $^{38,43}$ Therefore, SEC calculated with voltage drop over the repeating unit, $U_{\mathrm{rp}}(t)$, is a more meaningful performance metric for the actual operation and was evaluated separately (eq 5)

$$
\mathrm{SEC}_{\mathrm{rp}}=\frac{i A_{\mathrm{ED}} \int_{0}^{t} U_{\mathrm{rp}}(t) \mathrm{d} t}{\left(c_{\mathrm{TAN}}^{\mathrm{a}}(t)-c_{\mathrm{TAN}}^{\mathrm{a}}(0)\right) V_{\mathrm{a}} M_{\mathrm{N}}}
$$

Because $U_{\mathrm{rp}}(t)$ cannot be measured directly during BMEDMC experiments, voltage drops on electrodes, $U_{\text {ele, under }}$ different current densities were characterized independently and subtracted from $U(t)$ to determine $U_{\mathrm{rp}}(t)$. Specifically, the two-electrode compartments of the BMED cell were assembled without any membrane in between. The cell was filled with 0.4 mol L ${ }^{-1} \mathrm{Na}_{2} \mathrm{SO}_{4}$ solution and applied with constant currents to determine the voltage drops on electrodes due to electrode reactions and activation overpotential.

BMED-MC Process Modeling. To model the batch BMED-MC process, we couple the kinetics of several phenomena, including ion transport under applied current, ion dissociation equilibrium in the BMED cell compartments, and ammonia vapor permeation across the PVDF membrane in the $\mathrm{MC}$ cell. The production rate $\left(\mathrm{mol} \mathrm{s}^{-1}\right)$ of $\mathrm{OH}^{-}$and $\mathrm{H}^{+}$ at $\mathrm{BM}$ is proportional to the current density and the effective membrane area (eq 6)

$$
\frac{\mathrm{d} n_{\mathrm{OH}^{-}}}{\mathrm{d} t}=\frac{\mathrm{d} n_{\mathrm{H}^{+}}}{\mathrm{d} t}=\frac{i A_{\mathrm{ED}}}{F}
$$

The transport rate $\left(\mathrm{mol} \mathrm{s}^{-1}\right)$ of $\mathrm{Na}^{+}$and $\mathrm{SO}_{4}{ }^{2-}$ across CEM and AEM is determined by the current density and possible leakage of $\mathrm{OH}^{-}$and $\mathrm{H}^{+}$across CEM and AEM, respectively (eqs 7 and 8)..$^{39,44}$ The leakage rate is assumed to depend on the $\mathrm{OH}^{-}$concentration, $c_{\mathrm{OH}}-$, in the base compartment and $\mathrm{H}^{+}$concentration, $c_{\mathrm{H}}+$, in the acid compartment, current density, and membrane area. The leakage of any ion across the $\mathrm{BM}$ is assumed to be negligible

$$
\begin{aligned}
& \frac{\mathrm{d} n_{\mathrm{Na}^{+}}}{\mathrm{d} t}=\frac{i A_{\mathrm{ED}}}{F}-i h A_{\mathrm{ED}{ }^{\mathrm{OH}^{-}}} \\
& \frac{\mathrm{d} n_{\mathrm{SO}_{4}^{2-}}}{\mathrm{d} t}=\frac{i A_{\mathrm{ED}}}{2 F}-\frac{1}{2} i h A_{\mathrm{ED}^{c} \mathrm{H}^{+}}
\end{aligned}
$$

where $h$ is the leakage coefficient $\left(\mathrm{L} \mathrm{A}^{-1} \mathrm{~s}^{-1}\right)$ of IEMs and is assumed to be the same for both CEM and AEM in this study. The value of $h$ is fitted from experimental data.

The ammonia and ammonium concentrations in each stream and the stream $\mathrm{pH}$ at any time can be determined by solving nitrogen mass balance, ammonia-ammonium dissociation equilibrium (Figure S3A), and charge balance simultaneously. Dissociation equilibrium of carbonates and phosphates is considered for the urine stream (Figure S3B,C). Dissociation equilibrium of acetate is not included as acetic acid has a $\mathrm{pK}_{\mathrm{a}}$ of 4.75 and is thus nearly completely in its deprotonated form as acetate in the urine stream. Since the $\mathrm{pH}$ of the acid stream can be low (e.g., lower than 2), the sulfatebisulfate dissociation equilibrium is also taken into account for the acid stream (Figure S3D).

The total cell voltage, $U$, is the sum of voltage drops caused by solution resistances in compartments, membrane resistances, Donnan potentials (also known as Nernst potentials) across membranes, and voltage drops on electrodes (eq 9)

$$
U=\sum_{j} U_{j}+i\left(R_{\mathrm{AEM}}+R_{\mathrm{CEM}}+R_{\mathrm{BM}}\right)+U_{\mathrm{D}}+U_{\text {ele }}
$$

where $U_{j}$ is the voltage drop over solutions across each compartment, and subscript $j$ represents electrode, base, or acid compartments; $U_{\mathrm{D}}$ is Donnan potentials across membranes; $U_{\text {ele }}$ is the voltage drop on electrodes; and $R_{\mathrm{AEM}}, R_{\mathrm{CEM}}$, and $R_{\mathrm{BM}}$ are the specific resistances $\left(\Omega \mathrm{m}^{2}\right)$ of AEM, CEM, and $\mathrm{BM}$, respectively. The ion concentrations in each compartment are modeled individually for calculating the respective voltage drops using the following equation ${ }^{45}$

$$
U_{j}=\frac{i L_{j} U_{\mathrm{T}}}{F} \frac{1}{\sum_{k}\left|Z_{k}\right|^{2} c_{k, j} D_{k}}
$$

where $U_{\mathrm{T}}$ is the thermal voltage (i.e., $0.0256 \mathrm{~V}$ at room temperature); $F$ is Faraday constant $\left(96487 \mathrm{C} \mathrm{mol}^{-1}\right) ; Z_{k}, c_{k}$, and $D_{k}$ are the charge, molar concentration $\left(\mathrm{mol} \mathrm{m}^{-3}\right)$, and diffusion coefficient $\left(\mathrm{m}^{2} \mathrm{~s}^{-1}\right)$ of ion $k$ in compartment $j$; and $L_{j}$ is the thickness $(\mathrm{m})$ of compartment $j$.

Donnan potentials across the membranes exist due to the concentration difference as a result of selective ion migration. Donnan potentials across the CEM and AEM are small compared to the voltage drops across the compartments. Therefore, Donnan potentials across the IEMs are neglected in our models. However, the Donnan potential across the BM is larger than that across the IEMs and is estimated based on the $\mathrm{pH}$ difference between acid and base compartments (eq 11)

$$
U_{\mathrm{D}}=\frac{R T}{F} \ln \frac{c_{\mathrm{H}^{+}}^{\mathrm{a}}}{c_{\mathrm{H}^{+}}^{\mathrm{b}}}=0.0591 \Delta \mathrm{pH}
$$

where $c_{\mathrm{H}+}^{\mathrm{b}}$ and $c_{\mathrm{H}+}^{\mathrm{a}}$ are the $\mathrm{H}^{+}$molar concentration $\left(\mathrm{mol} \mathrm{L}{ }^{-1}\right)$ of base and acid streams, respectively.

Voltage drop on electrodes, $U_{\text {ele }}$, is the sum of the reversible open-circuit voltage of electrode reactions and the activation overvoltage required to drive finite current. ${ }^{47}$ The activation overvoltage can be modeled using the simplified ButlerVolmer equation (eq 12)

$$
U_{\text {ele }}=U_{\text {rev }}+U_{\text {act }}=U_{\text {rev }}+\alpha \arcsin h\left(\frac{i}{2 i_{0}}\right)
$$

where $U_{\text {rev }}$ and $U_{\text {act }}$ are the reversible open-circuit voltage and activation overvoltage, respectively; $\alpha$ is the charge-transfer coefficient $(\mathrm{V})$ for electrodes; and $i_{0}$ is the exchange current density $\left(\mathrm{A} \mathrm{m}^{-2}\right)$ on the electrode surface. $U_{\text {rev }}, \alpha$, and $i_{0}$ are fitted from the electrode characterization experiments.

Ammonia vapor flux across the PVDF membrane in the MC cell, $J_{\mathrm{NH}_{3}}$, is driven by the vapor pressure difference. Ammonia 

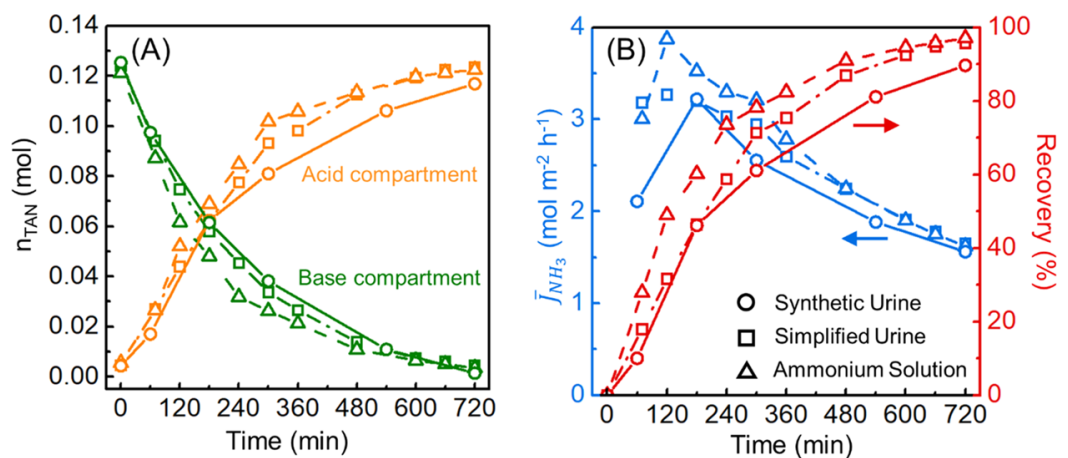

Figure 2. (A) TAN mass in the mole in the acid and base compartments; (B) average ammonia vapor flux and ammonia recovery as a function of time over the duration of $12 \mathrm{~h}$ of operation. Square, triangle, and round symbols represent simplified urine, ammonium solution, and synthetic urine experiments, respectively. A constant current density of $60 \mathrm{~mA} \mathrm{~cm}{ }^{-2}$ was applied at the beginning and was cut off after the base compartment $\mathrm{pH}$ exceeded 12.0.

vapor pressure of each stream is related to the ammonia concentration in the liquid phase by Henry's constant (eq 13). The ammonia vapor flux can be written as

$$
J_{\mathrm{NH}_{3}}=L_{\mathrm{p}}\left(p_{\mathrm{NH}_{3}}^{\mathrm{b}}-p_{\mathrm{NH}_{3}}^{\mathrm{a}}\right)=L_{\mathrm{p}} k_{\mathrm{H}}\left(c_{\mathrm{NH}_{3}}^{\mathrm{b}}-c_{\mathrm{NH}_{3}}^{\mathrm{a}}\right)
$$

where $L_{\mathrm{p}}$ is ammonia permeability $\left(\mathrm{mol} \mathrm{m}^{-2} \mathrm{~h}^{-1} \mathrm{~Pa}^{-1}\right)$ across the PVDF membrane; $p_{\mathrm{NH}_{3}}^{\mathrm{b}}$ and $p_{\mathrm{NH}_{3}}^{\mathrm{a}}$ are the ammonia vapor pressure of base and acid streams, respectively; $c_{\mathrm{NH}_{3}}^{b}$ and $c_{\mathrm{NH}_{3}}^{\mathrm{a}}$ are the ammonia concentrations in base and acid streams, respectively; and $k_{\mathrm{H}}$ is Henry's constant $\left(\mathrm{Pa} \mathrm{M}^{-1}\right)$ of ammonia at room temperature.

To design a continuous BMED-MC system (Figure 1B), BMED and MC units are modeled individually with their mass transfer coupled. With a predetermined target $\mathrm{pH}$ to achieve by BMED, the stream composition change can be quantified and thus the required BMED membrane area can be determined at varying current density. As solute concentrations vary along the flow direction in the BMED unit, the logarithmic mean of influent and effluent concentrations was used to evaluate solution ohmic resistance and energy consumption of the BMED unit. ${ }^{43}$ All acid, base, and salt chamber thicknesses were assumed to be $1 \mathrm{~mm}$. Ammonia recovery from urine to acid streams in the $\mathrm{MC}$ unit can be described regarding the $\mathrm{MC}$ membrane area by the differential equation

$$
\frac{\mathrm{d} \dot{n}_{\mathrm{TAN}}^{\mathrm{a}}}{\mathrm{d} A_{\mathrm{MC}}}=-\frac{\mathrm{d} \dot{n}_{\mathrm{TAN}}^{\mathrm{b}}}{\mathrm{d} A_{\mathrm{MC}}}=J_{\mathrm{NH}_{3}}
$$

where $n_{\text {TAN }}^{\dot{\mathrm{a}}}$ and $n_{\text {TAN }}^{\dot{\mathrm{b}}}$ are the TAN molar mass flow rate (mol $\mathrm{h}^{-1}$ ) of acid and base streams, respectively. BMED-MC modeling was performed by numerically solving the system of equations using MATLAB (code provided in the Supporting Information). The key parameters used in solving the equations are listed in Table S2, where leakage coefficient and ammonia permeability values were fitted from experimental data and other parameter values were taken from the literature. ${ }^{16,39}$

\section{RESULTS AND DISCUSSION}

High Ammonia Recovery Can Be Achieved. Experiments with synthetic urine, simplified urine, and ammonium solution (Table S1) at a constant current density of $60 \mathrm{~mA}$ $\mathrm{cm}^{-2}$ demonstrate that ammonia nitrogen can be efficiently recovered via the BMED-MC process. The mass of TAN monotonically decreased over time in the urine stream and monotonically increased in the acid stream (Figure 2A). The mass balance of TAN in the system was checked, and a loss of less than $9 \%$ was observed, which was possibly due to the leakage of ammonia vapor from the system, solution volume change caused by osmosis, and measurement error. Over 50\% of TAN in the urine stream was recovered by the acid stream in the first $4 \mathrm{~h}$, while $90-95 \%$ of TAN was recovered after $12 \mathrm{~h}$ (Figure 2B). The average ammonia flux generally decreased over time (Figure 2B) because of the decreasing ammonia concentration difference between the urine and acid streams, which is the driving force for the ammonia vapor flux (eq 13). We note that the average flux briefly increased at the beginning due to a combined effect of the decreasing TAN and the increasing $\mathrm{pH}$ in the urine stream, which is discussed in the next section. If the batch mode operation of BMED-MC was performed for a longer duration, the ammonia flux is expected to further decrease toward zero while the recovery will approach $100 \%$.

The experiments with synthetic urine showed a lower ammonia flux and recovery in the first $8 \mathrm{~h}$ compared to the simplified urine and ammonium sulfate solution experiments (Figure 2B). The $\mathrm{pH}$ of the base stream exceeded 12.0 and was maintained over 12.0 after 110,110 , and $75 \mathrm{~min}$ in the synthetic urine, simplified urine, and ammonium solution experiments, respectively (Figure S4). As ammonia concentration is affected by solution $\mathrm{pH}$, the lower flux in the synthetic urine experiment was possibly due to the $\mathrm{pH}$ buffering capacity of carbonate and phosphate alkalinity, which slowed down the $\mathrm{pH}$ increase in the urine stream. Although the overall flux and recovery performance difference between the three different urine streams were small, the effects of background strong electrolytes (e.g., $\mathrm{Na}^{+}, \mathrm{K}^{+}, \mathrm{Cl}^{-}, \mathrm{SO}_{4}{ }^{2-}$ ), alkalinity buffer electrolytes (e.g., carbonates and phosphates), and organics should not be neglected. Therefore, the synthetic urine solution was used as feed urine for the rest of the study.

Ammonia Flux Increases with Current Density. To investigate the influence of current density, BMED-MC performance was evaluated with different current densities (10, 20,40 , and $60 \mathrm{~mA} \mathrm{~cm}{ }^{-2}$ ). With a lower current density, the decrease of TAN mass in the urine stream and increase of TAN mass in the acid stream were both slower (Figure 3A). The model captures the overall evolution of the TAN mass in both streams with reasonable accuracy, although it slightly overestimated the TAN mass of the acid stream, possibly due to ammonia leakage. There was around $10-20 \% \mathrm{~N}$ loss over 

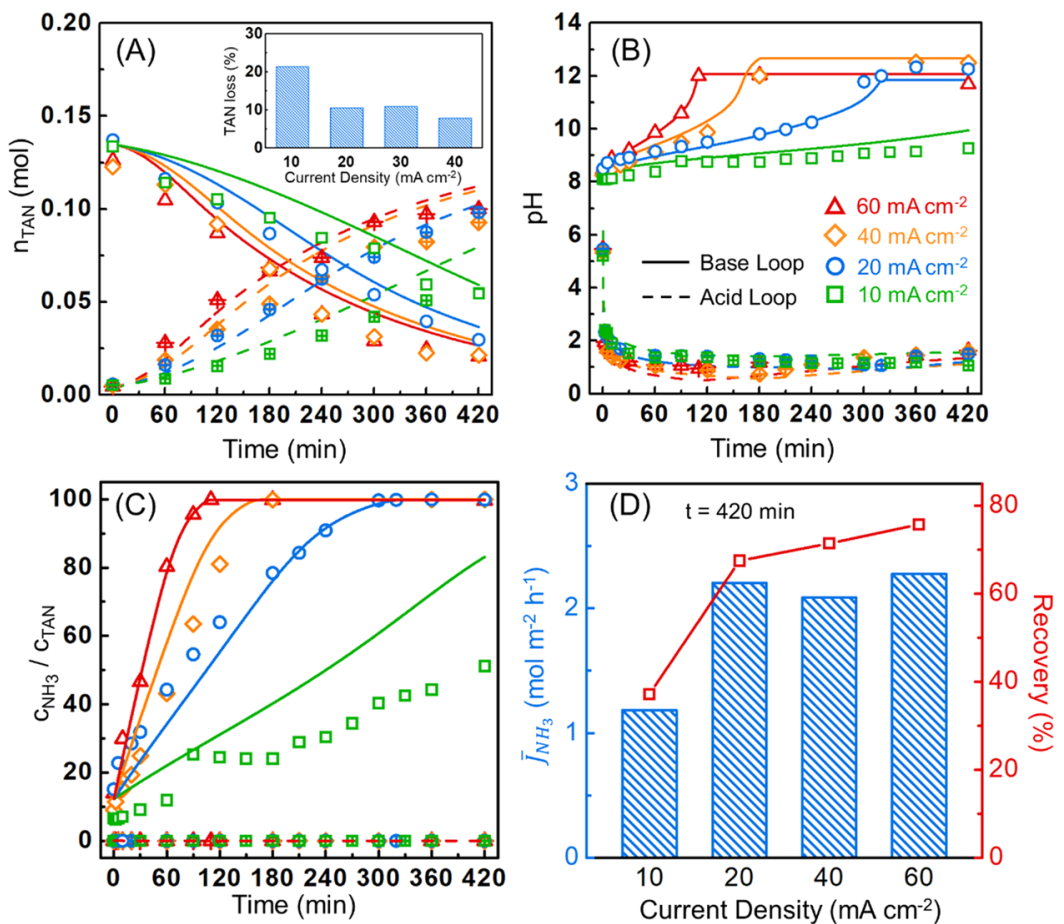

Figure 3. (A) Concentration of TAN in the base and acid compartments as a function of time under different current densities. The inset shows overall $\mathrm{N}$ loss (mass balance evaluation) during experiments under different current densities. (B) $\mathrm{pH}$ variation and (C) ammonia fraction in the base and acid compartments as a function of time under different current densities. (D) Recovery of ammonia and average ammonia flux for $t=420$ min as a function of current density. Dots represent experimental data, and smooth curves represent model predictions.

the $7 \mathrm{~h}$ operation evaluated with TAN mass balance (Figure $3 \mathrm{~A}$ inset).

The applied current was cut off at 320, 180, and $110 \mathrm{~min}$ under 20, 40, and $60 \mathrm{~mA} \mathrm{~cm}^{-2}$, respectively, when the urine $\mathrm{pH}$ reached 12.0. The applied current was not cut off under 10 $\mathrm{mA} \mathrm{cm}{ }^{-2}$ as the urine $\mathrm{pH}$ did not exceed 12.0 during the entire experiment. The critical cutoff point was selected to maximize the driving force of ammonia transport in MC because over $99.8 \%$ of the TAN in the urine stream will be in ammonia form when $\mathrm{pH}$ exceeds 12.0. However, we note that reducing the critical $\mathrm{pH}$ may result in lower energy consumption (at the cost of kinetics) and the choice of critical $\mathrm{pH}$ in a continuous operation system is further discussed in the following sections. The $\mathrm{pH}$ of the urine stream first increased slowly when $\mathrm{pH}$ was less than 11 and then increased sharply to over 12 and remained stable after the current was cut off (Figure 3B). This is because near $90 \%$ of the TAN in the initial urine stream was in ammonium form (Figure 3C), which, together with bicarbonates and monohydrogen phosphates, functioned as a $\mathrm{pH}$ buffer when $\mathrm{OH}^{-}$was produced by BMED. As the $\mathrm{pH}$ exceeds 11 , the ammonium in the urine stream was mostly converted to ammonia (Figure S3A) and thus $\mathrm{pH}$ started to increase more rapidly due to the depletion of buffering capacity. The $\mathrm{pH}$ remained stable after the current was cut off because no $\mathrm{OH}^{-}$was consumed during the ammonia recovery. A higher current density increased $\mathrm{pH}$ of the urine stream faster because the $\mathrm{OH}^{-}$production rate is proportional to current density. Meanwhile, the $\mathrm{pH}$ of the acid stream decreased sharply from near 6 to less than 1 before slowly recovering to around 2 (Figure $3 \mathrm{~B}$ ). The initial decrease of $\mathrm{pH}$ is attributable to the absence of buffering capacity when BMED started to produce $\mathrm{H}^{+}$in the acid stream. As ammonia was recovered by the acid stream, $\mathrm{H}^{+}$was consumed and ammonia became ammonium, which contributes to the $\mathrm{pH}$ increase over time after the current was cut off.

As average ammonia flux decreased while recovery increased over time, we calculate and compare the average flux and recovery over the first $7 \mathrm{~h}$ (i.e., $420 \mathrm{~min}$ ) to fairly evaluate the effect of current density. The average ammonia flux increased from 1.18 to $2.28 \mathrm{~mol} \mathrm{~m}^{-2} \mathrm{~h}^{-1}$, while recovery increased from 37.2 to $75.7 \%$ as the current density increased from 10 to 60 $\mathrm{mA} \mathrm{cm}{ }^{-2}$ (Figure 3D). The driving force for ammonia vapor flux depended solely on the ammonia concentration in the urine stream because ammonia concentration in the acid stream was always zero as all nitrogen was in the ammonium form due to the low $\mathrm{pH}$ (Figure 3C). Before the current was cut off, the ammonia concentration in the urine stream increased because of more ammonium being converted to ammonia than the amount of ammonia recovered to the acid stream. A higher current density increased $\mathrm{pH}$ faster, which resulted in a faster increase in ammonia concentration and thus a larger driving force. The higher overall average flux and recovery at higher current density result from a larger average driving force for ammonia transport, i.e., a larger average ammonia concentration difference across the PVDF membrane in $\mathrm{MC}$.

Energy Consumption Increases with Current Density. Energy consumption of the BMED-MC process was evaluated under different current densities of 10,20,40, and $60 \mathrm{~mA}$ $\mathrm{cm}^{-2}$. The cell stack voltage was broken down to voltage drops across different components. When the $\mathrm{BMED}-\mathrm{MC}$ process was operated under a constant current, the cell stack voltage varied over time following a characteristic profile with two stages (Figure 4A). The cell voltage dropped sharply in the first several minutes, which was more obvious at a higher current density and then stabilized and remained constant in a quasi- 

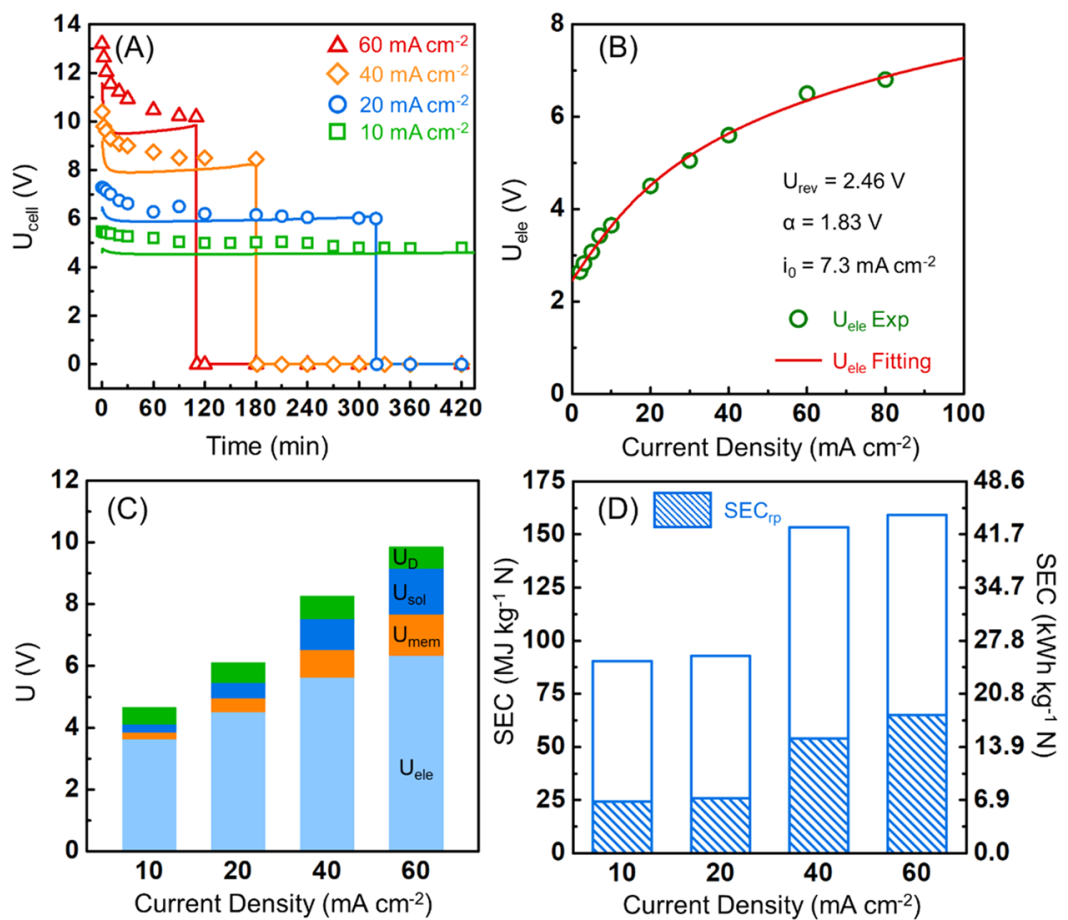

Figure 4. (A) Cell voltage of the BMED cell as a function of time under different current densities. (B) Voltage drops on electrodes as a function of current density quantified by the electrode characterization experiment. (C) Donnan potential, voltage drops on membranes, solutions, and electrodes as a function of current density before the current was cut off. (D) SEC of the overall BMED cell (entire column) and SEC of the repeating unit (shadow part) as a function of current density. Dots represent experimental data, and smooth curves represent model predictions.

steady stage until the current was cut off. The cell voltage during the quasi-steady stage was larger under a higher current density. The cell voltage dropped to zero when the applied current was cut off at 320,180, and 110 min under 20, 40, and $60 \mathrm{~mA} \mathrm{~cm}{ }^{-2}$, respectively. The sharp voltage drop at the beginning was mainly due to the water dissociation by BM that increased conductivities of base and acid streams. The initial feed stream in the acid compartment was a dilute ammonium sulfate solution. The solution resistance decreased rapidly when BMED started, which corresponds to a sharp $\mathrm{pH}$ drop of the acid stream (Figure 3B).

To quantify the voltage drop over the electrodes, we performed an electrode characterization experiment where the two electrodes were assembled with $0.4 \mathrm{M} \mathrm{Na}_{2} \mathrm{SO}_{4}$ solution as the electrolyte in between, without any IEM or BM. The cell voltage was measured with different densities. The cell voltage drop increased with current density (Figure 4B) and can be decomposed to a reversible open-circuit voltage and an activation overvoltage (eq 12). The fitted reversible voltage was $2.46 \mathrm{~V}$, which represents the reversible water electrolysis potential on the titanium-stainless steel electrode pair and is independent of the current density. The activation overvoltage increased with current density, which reflects electrode kinetics. We assumed the voltage drop on electrodes to be constant over time.

Voltage drop over the repeating unit was also split into voltage drops on membranes, solutions in all compartments, and Donnan potential across the BM (Figure 4C). The voltage drop on membranes increased linearly with current density as the membrane-specific resistances were regarded as constants. The voltage drop over solution was roughly proportional to the current density as the solution composition was similar under different current densities at the point when the current was cut off. The Donnan potential across the BM was approximately constant under different current densities as the $\mathrm{pH}$ differences between the urine and the acid streams were similar, i.e., around 10 (Figure $3 \mathrm{~B}$ ). As compared to the voltage drop over unit that would repeat in a large stack with multiple units, the voltage drop over the electrodes contributed $64-79 \%$ of the cell stack voltage in this single-unit BMED cell. However, for full-scale system containing tens or hundreds of repeating units, the cell stack voltage will be mainly attributable to the repeating units as the voltage drop on the electrodes remains the same regardless of the number of repeating unit. ${ }^{43}$ We evaluate the SEC of the BMED-MC process with and without considering the contribution of the electrodes. The SEC ranges from 90.3 to $159.1 \mathrm{MJ} \mathrm{kg}^{-1} \mathrm{~N}$ under different current densities considering the contribution from the electrodes, which is directly relevant to the experimental system used in this study. However, neglecting the contribution from electrodes, which is more relevant to practical BMED systems with many (i.e., tens or even over a hundred) repeating units, the SEC will be substantially lower, ranging from 24.4 to $65.1 \mathrm{MJ} \mathrm{kg}^{-1} \mathrm{~N}$ (Figure 4D).

Energy Consumption of BMED-MC vs. Other Ammonia Recovery Processes. To facilitate comparing the energy consumption of the BMED-MC process and existing ammonia recovery processes, we further evaluated the performance of a continuous BMED-MC process, treating 1 $\mathrm{m}^{3} \mathrm{~h}^{-1}$ source-separated urine with the experimentally validated model. The critical $\mathrm{pH}$ of the urine stream to achieve by BMED was chosen as a key design parameter. To achieve a target critical $\mathrm{pH}$ of the urine stream, lower operating current density can reduce energy consumption but on the cost of requiring more membrane area and thus higher capital cost (Figure 5A). A higher critical $\mathrm{pH}$ consumes more energy as 

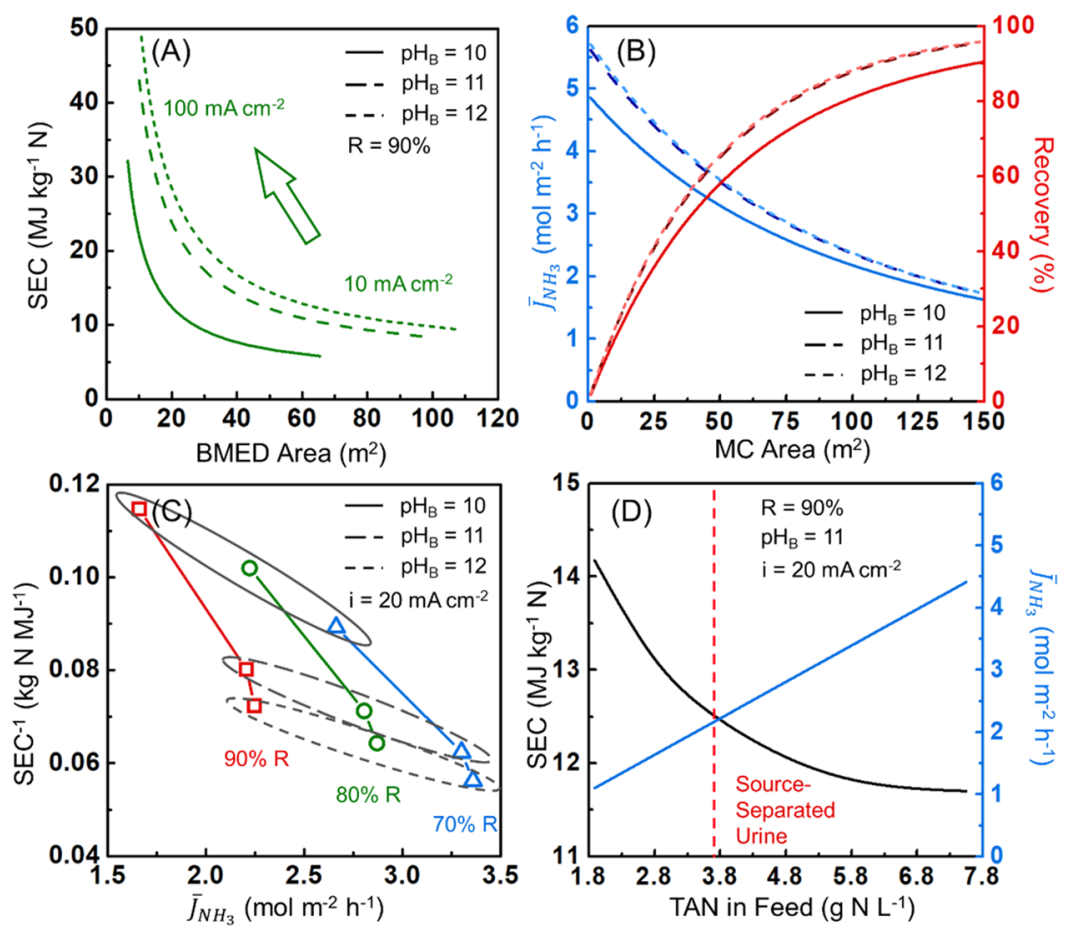

Figure 5. (A) SEC of a continuous BMED-MC system $\left(1 \mathrm{~m}^{3} \mathrm{~h}^{-1}\right.$ feed capacity) to achieve different target urine stream pH as a function of the required BMED membrane area. TAN recovery of $90 \%$ is assumed. (B) Average recovery flux and recovery as a function of the MC membrane area at different target urine stream $\mathrm{pH}$. (C) Tradeoff of $\mathrm{SEC}^{-1}$ and average recovery flux as a function of target urine stream $\mathrm{pH}$ to achieve different recovery. A current density of $20 \mathrm{~mA} \mathrm{~cm}{ }^{-2}$ is assumed. (D) SEC and average recovery flux as a function of feed TAN concentration. Assume target recovery is $90 \%$, target urine $\mathrm{pH}$ is 11 , and current density is $20 \mathrm{~mA} \mathrm{~cm}{ }^{-2}$.

more hydroxide ions need to be produced via water dissociation. On the other hand, a higher critical $\mathrm{pH}$ enhances ammonia recovery in MC. However, as $99 \%$ of TAN is in ammonia form when urine $\mathrm{pH}$ exceeds 11 , further increasing urine $\mathrm{pH}$ beyond 11 has negligible impact on ammonia flux and recovery (Figure $5 \mathrm{~B}$ ).

A tradeoff between energy consumption and kinetics exists when varying the critical $\mathrm{pH}$. To achieve a certain recovery, a higher critical $\mathrm{pH}$ can enhance ammonia recovery flux but consume more energy (Figure 5C). However, increasing the critical $\mathrm{pH}$ beyond 11 only results in the marginal improvement of ammonia flux, yet it continues to increase the energy consumption. With a critical $\mathrm{pH}$ of 11 , the energy required to achieve a $90 \%$ ammonia recovery in a continuous process is $12.5 \mathrm{MJ} \mathrm{kg}^{-1} \mathrm{~N}$, with an average ammonia flux of $2.2 \mathrm{~mol} \mathrm{~m}^{-2}$ $\mathrm{h}^{-1}$, which is less than half of that in the batch process due to the higher recovery, lower critical $\mathrm{pH}$, and smaller salt chamber thickness (i.e., $1 \mathrm{~mm}$ ) used for continuous mode calculation. Finally, the effect of feed TAN concentration on process performance is also evaluated, as different feed solutions are used in the literature. Our analysis shows that a higher initial TAN concentration can result in higher ammonia flux and lower SEC (Figure 5D).

SEC of existing ammonia recovery processes along with ammonia flux under specific process conditions from the literature are summarized (Table 1 ). We note that Table 1 is not an exhaustive list of studies on ammonia recovery from urine or wastewater and it only includes studies reporting sufficient information for the listed parameters. Minimal BM cell system uses a cell configuration without AEMs in which ammonium migrates across CEMs to be concentrated and recovered via an $\mathrm{MC}$ by an external acid stream. IMD-AC recovers ammonia from urine with membrane distillation where the isothermal condition suppresses the undesired water transport and thus improves selectivity for ammonia flux as compared to conventional membrane distillation. ES integrates an acid trap chamber next to the cathodic chamber of an electrochemical cell separated by a gas-permeable membrane. The $\mathrm{pH}$ of urine increases in the cathodic chamber under applied voltage, and ammonia is recovered by the acid trap chamber. We note that performance varies between different variants of electrochemical stripping systems (e.g., $\mathrm{H}_{2}$ recycling system $^{21,22}$ and gas-diffusion-electrode system, ${ }^{23}$ etc.) but the basic working principles are all based on the water electrolysisassisted ammonium-ammonia conversion at the cathode. Capacitive membrane stripping integrates a capacitive deionization unit with a membrane contactor for ammonia recovery. Ammonia selectively accumulates in the flowing cathode followed by a stripping step within the membrane contactor.

BMED-MC shows potential for energy saving as compared with the existing ammonia recovery processes, though the recovery flux varies between processes (Table 1). The energy consumption in the IMD-AC process (i.e., 7.9 $\mathrm{MJ} \mathrm{kg}^{-1} \mathrm{~N}$ ) is mainly consumed to provide the vaporization enthalpy of volatile ammonia and undesired water. The much higher ammonia flux in IMD-AC is mainly due to the higher solution temperature, as ammonia vapor pressure increases exponentially with temperature, as governed by the ClausiusClapeyron relation. Although IMD-AC has a lower SEC than BMED-MC, it consumes external acid for ammonia stripping, while BMED-MC produces acid internally.

Similar to the BMED-MC process, the energy inputs in the minimal BM cell system $\left(18.3 \mathrm{MJ} \mathrm{kg}^{-1} \mathrm{~N}\right)$, ES process $(40.0$ $\left.\mathrm{MJ} \mathrm{kg}{ }^{-1} \mathrm{~N}\right)$, and CapAmm (35.6 $\mathrm{MJ} \mathrm{kg}^{-1} \mathrm{~N}$ ) are mainly 
Table 1. Comparison of Ammonia Recovery Processes

\begin{tabular}{|c|c|c|c|c|c|c|}
\hline process & mode & $\begin{array}{l}\text { feed TAN } \\
\left(\mathrm{mg} \mathrm{N} \mathrm{L}^{-1}\right)\end{array}$ & $\begin{array}{l}\text { recovery } \\
(\%)\end{array}$ & $\begin{array}{l}\text { external acid for } \\
\text { stripping }\end{array}$ & $\begin{array}{c}\text { flux } \\
\left(\mathrm{mol} \mathrm{m} \mathrm{m}^{-2} \mathrm{~h}^{-1}\right)\end{array}$ & $\operatorname{SEC}\left(\mathrm{MJ} \mathrm{kg}^{-1} \mathrm{~N}\right)$ \\
\hline $\begin{array}{l}\text { BMED-MC (this study, } \\
\text { experimental) }\end{array}$ & batch & 3772 & 67.5 & $\mathrm{~N} / \mathrm{A}$ & 2.2 & $\begin{array}{l}25.8^{a} \text { (excluding } \\
\text { electrode) }\end{array}$ \\
\hline $\begin{array}{l}\text { BMED-MC (this study, from } \\
\text { model) }\end{array}$ & continuous & 3772 & 90.0 & $\mathrm{~N} / \mathrm{A}$ & 2.2 & $\begin{array}{l}12.5^{a} \text { (excluding } \\
\text { electrode) }\end{array}$ \\
\hline minimal $\mathrm{BM}$ cell $^{29}$ & continuous & 1750 & 78.0 & $3 \mathrm{M} \mathrm{H}_{2} \mathrm{SO}_{4}$ & 2.4 & 18.3 \\
\hline $\mathrm{IMD}^{-A C^{16}}$ & batch & 7000 & 48.2 & $0.75 \mathrm{M} \mathrm{HAc}$ & 13.9 & 7.9 \\
\hline $\mathrm{ES}^{17}$ & continuous & 7490 & 50.0 & $1 \mathrm{M} \mathrm{H}_{2} \mathrm{SO}_{4}$ & 3.0 & 40.0 \\
\hline CapAmm $^{19}$ & continuous & 40 & 38.1 & $0.5 \mathrm{M} \mathrm{H}_{2} \mathrm{SO}_{4}$ & 0.034 & 35.6 \\
\hline
\end{tabular}

${ }^{a_{T}}$ The current density was $20 \mathrm{~mA} \mathrm{~cm}{ }^{-2}$. Critical $\mathrm{pH}$ was 12 for batch mode experiments and 11 for continuous mode modeling. We note that energy consumption on electrodes was excluded, which has been justified for a full-scale system.

attributable to electrode reactions, ohmic resistance of solutions and membranes, and ion transport across membranes. However, ES and CapAmm differ from BMED-based systems in that the energy consumption on electrodes cannot be excluded in ES and CapAmm SEC analyses as electrodes directly contribute to ammonia recovery. Specifically, ES utilizes water electrolysis on electrodes to increase urine $\mathrm{pH}$, and CapAmm utilizes electroadsorption by the electrodes to concentrate ammonium accompanied by oxygen reduction. Thus, the SEC of the BMED-based systems (e.g., $25.8 \mathrm{MJ} \mathrm{kg}^{-1}$ $\mathrm{N}$ for batch mode and $12.5 \mathrm{MJ} \mathrm{kg}^{-1} \mathrm{~N}$ for continuous mode in this study, excluding contributions from the electrode reaction) is lower than the other two electrochemical processes (i.e., ES and CapAmm). Furthermore, a continuous external acid input is not required by the BMED-MC process while indispensable to most other processes, including the minimal BM cell system. Compared to the energy demand of current nitrogen management, the SEC of the BMED-MC process is much lower than that of the Haber-Bosch process (32.0-69.5 MJ kg $\mathrm{kg}^{-1} \mathrm{~N}$ ) and is comparable to that of nitrificationdenitrification $\left(8.3-23.4 \mathrm{MJ} \mathrm{kg}^{-1} \mathrm{~N}\right)$.

The analysis above provides only a preliminary comparison of the SEC between different ammonia recovery processes but not a definitive conclusion regarding which process is the most competitive. Direct comparison of SEC between processes is in theory strictly fair only when both the separation and kinetics achieved by such processes are identical. In our context, the information defining the "separation" includes the concentrations of ammonium in both the feed solution and the stripping solution, the percentage of ammonia recovery, and the chemistry of the nitrogen product. For example, comparing the SEC to obtain $1 \mathrm{~kg} \mathrm{~N}$ in the form of pure ammonia from the Haber-Bosch process to $1 \mathrm{~kg} \mathrm{~N}$ in the form of $\left(\mathrm{NH}_{4}\right)_{2} \mathrm{SO}_{4}$ in an aqueous solution is not fair in scientific principle but may nonetheless be justified from the practical perspective of producing $1 \mathrm{~kg}$ of bioavailable nitrogen.

Even if the separation is the same, SEC also strongly depends on kinetics as demonstrated by the strong dependence of ammonia flux on current density (Figure 3D) or critical $\mathrm{pH}$ (Figure 5C). Such an interdependence between SEC and production rate has been theoretically and experimentally studied for different desalination processes. ${ }^{39,48,49}$ For processes of similar nature, e.g., electrochemical ammonia recovery using ion-exchange membranes, such an interdependence requires that we should compare SEC using the same flux. Unfortunately, due to the limited number of studies on this topic, a comprehensive and systematic comparison of SEC between different processes at the same kinetics is not possible. Nonetheless, the results from this study suggest that BMED-
MC has a balanced advantage considering both SEC and the ammonia flux when compared to ES and CapAmm. We note that ammonia flux is also dependent on the TAN concentration of the feed solution, which suggests that the separation achieved has intrinsic impact on not only the SEC but also the kinetics (Figure 5D). For example, the very low TAN in the study of CapAmm explains the very low ammonia flux. For processes of a very different nature, the quantification of kinetics using ammonia flux becomes even less meaningful. This is because the practical relevance of flux is associated with the system size (to achieve a certain capacity) and thus the capital cost, but processes of a very different nature have dramatically different unit costs per area of the system. For example, IMD-AC uses only low-cost hydrophobic membranes, whereas the electrochemical processes use more expensive ion-exchange membranes (ES and CapAmm would also require two additional electrodes per cell pair).

Considering both SEC, ammonia flux, and the capital cost per unit area of the cell, it appears that IMD-AC outperforms all electrochemical approaches for ammonia recovery, including BMED-MC. However, IMD-AC relies on the supply of acid as a stripping solution. Not only the energy cost and environmental footprint of the centralized production of acid must be considered when comparing to BMED-MC, but the logistic and safety challenges to continuously supply acid to distributed sources cannot be overlooked. To a large extent, BMED-MC accomplishes the distributed and safe production of acid (and base), thereby circumventing those challenges at the cost of slightly more energy consumption. However, $\mathrm{BMED}-\mathrm{MC}$ is expected to have a higher capital cost than IMD-AC due to the use of ion-exchange membranes. A more reliable comparison between BMED-MD, IMD-AC, and other processes requires a comprehensive technoeconomic analysis, which not only is beyond the scope of this study but also requires more data than what is presently available.

Implications. Our study demonstrates that the BMED$\mathrm{MC}$ process can be a very effective alternative for ammonia removal and recovery from source-separated urine. Compared with other ammonia recovery processes that require additional acid input, BMED-MC allows for the selective recovery of ammonia by increasing the $\mathrm{pH}$ of the urine stream and producing an acid stream via water dissociation across the bipolar membranes. Given that the solution phase ammonia equilibrates with gaseous ammonia rapidly, ammonia permeates through the gas-permeable membrane in the membrane contactor and is captured by the acid stream and recovered as an ammonium salt that can be supplied as a fertilizer. While ammonium sulfate was produced in this study for ammonia recovery, alternative salts (e.g., ammonium 
phosphate and ammonium nitrate) could also be produced as higher-value fertilizers using other salt solutions in BMED. Importantly, the BMED-MC process (when scaled up) is relatively energy-efficient and does not require continuous external inputs of acids.

Further study is needed to evaluate the BMED-MC performance with a large-scale system and under continuous mode in longer-term operation. Potential membrane scaling and fouling by inorganic (e.g., magnesium and calcium) and complex organic components in the real urine should be evaluated to fully understand the practical potential of the process for long-term operation. Technoeconomic assessments are also needed to quantify the capital and operating expenditure of BMED-MC as IEMs and BM are relatively expensive. Nonetheless, the process has shown significant potential to be cost-competitive for recovering ammonia from source-separated urine.

\section{ASSOCIATED CONTENT}

\section{SI Supporting Information}

The Supporting Information is available free of charge at https://pubs.acs.org/doi/10.1021/acs.est.1c05316.

Photographic image of the BMED-MC system (Figure $S 1)$; $I-V$ curve of the used bipolar membrane under synthetic urine and a $0.01 \mathrm{M}\left(\mathrm{NH}_{4}\right)_{2} \mathrm{SO}_{4}$ solution (Figure S2); dissociation equilibrium of ammonia, carbonic acid, phosphoric acid, and sulfuric acid (Figure S3); $\mathrm{pH}$ variation in the acid and base chambers during the $12 \mathrm{~h} \mathrm{BMED-MC}$ experiments (Figure S4); initial compositions of the synthetic urine, simplified urine, and ammonium solution (Table S1); key parameters used in the BMED-MC modeling (Table S2); and MATLAB code used in the BMED-MC modeling (PDF)

\section{AUTHOR INFORMATION}

\section{Corresponding Author}

Shihong Lin - Department of Civil and Environmental Engineering, Vanderbilt University, Nashville, Tennessee 37235-1831, United States; Department of Chemical and Bimolecular Engineering, Vanderbilt University, Nashville, Tennessee 37235-1831, United States; (1) orcid.org/00000001-9832-9127; Email: shihing.lin@vanderbilt.edu

\section{Authors}

Yujiao Li - Department of Civil and Environmental Engineering, Vanderbilt University, Nashville, Tennessee 37235-1831, United States; Beijing Engineering Research Center of Process Pollution Control, Institute of Process Engineering, Innovation Academy for Green Manufacture, Chinese Academy of Sciences, Beijing 100190, China; University of Chinese Academy of Sciences, Beijing 100049, China

Ruoyu Wang - Department of Civil and Environmental Engineering, Vanderbilt University, Nashville, Tennessee 37235-1831, United States

Shaoyuan Shi - Beijing Engineering Research Center of Process Pollution Control, Institute of Process Engineering, Innovation Academy for Green Manufacture, Chinese Academy of Sciences, Beijing 100190, China; University of Chinese Academy of Sciences, Beijing 100049, China; 이이.org/ 0000-0002-0205-231X
Hongbin Cao - Beijing Engineering Research Center of Process Pollution Control, Institute of Process Engineering, Innovation Academy for Green Manufacture, Chinese Academy of Sciences, Beijing 100190, China; University of Chinese Academy of Sciences, Beijing 100049, China; (1) orcid.org/0000-0001-5968-9357

Ngai Yin Yip - Department of Earth and Environmental Engineering and Columbia Water Center, Columbia University, New York 10027-6623, United States

Complete contact information is available at:

https://pubs.acs.org/10.1021/acs.est.1c05316

\section{Author Contributions}

${ }^{\nabla}$ Y.L. and R.W. contributed equally to this work.

Notes

The authors declare no competing financial interest.

\section{ACKNOWLEDGMENTS}

The authors are grateful for the support from National Science Foundation (1903685 for S.L. and R.W. and 1903705 for N.Y.Y.) and the Chinese Scholarship Council (201904910827 for Y.L.).

\section{REFERENCES}

(1) Bohlool, B. B.; Ladha, J. K.; Garrity, D. P.; George, T. Biological Nitrogen Fixation for Sustainable Agriculture: A Perspective. Plant Soil 1992, 141, 1-11.

(2) Robertson, G. P.; Vitousek, P. M. Nitrogen in Agriculture: Balancing the Cost of an Essential Resource. Annu. Rev. Environ. Resour. 2009, 34, 97-125.

(3) Erisman, J. W.; Sutton, M. A.; Galloway, J.; Klimont, Z.; Winiwarter, W. How a Century of Ammonia Synthesis Changed the World. Nat. Geosci. 2008, 1, 636-639.

(4) Conley, D. J.; Paerl, H. W.; Howarth, R. W.; Boesch, D. F.; Seitzinger, S. P.; Havens, K. E.; Lancelot, C.; Likens, G. E. Ecology Controlling Eutrophication: Nitrogen and Phosphorus. Science 2009, 323, 1014-1015.

(5) Rahman, S. M.; Eckelman, M. J.; Onnis-Hayden, A.; Gu, A. Z. Life-Cycle Assessment of Advanced Nutrient Removal Technologies for Wastewater Treatment. Environ. Sci. Technol. 2016, 50, 30203030.

(6) Wett, B. Development and Implementation of a Robust Deammonification Process. Water Sci. Technol. 2007, 56, 81-88.

(7) Fowler, D.; Coyle, M.; Skiba, U.; Sutton, M. A.; Cape, J. N.; Reis, S.; Sheppard, L. J.; Jenkins, A.; Grizzetti, B.; Galloway, J. N.; Vitousek, P.; Leach, A.; Bouwman, A. F.; Butterbach-Bahl, K.; Dentener, F.; Stevenson, D.; Amann, M.; Voss, M. The Global Nitrogen Cycle in the Twentyfirst Century. Philos. Trans. R. Soc. B Biol. Sci. 2013, 368, No. 20130164.

(8) Mulder, A. The Quest for Sustainable Nitrogen Removal Technologies. Water Sci. Technol. 2003, 48, 67-75.

(9) Maurer, M.; Schwegler, P.; Larsen, T. A. Nutrients in Urine: Energetic Aspects of Removal and Recovery. Water Sci. Technol. 2003, 48, 37-46.

(10) Karak, T.; Bhattacharyya, P. Human Urine as a Source of Alternative Natural Fertilizer in Agriculture: A Flight of Fancy or an Achievable Reality. Resour. Conserv. Recycl. 2011, 55, 400-408.

(11) Luther, A. K.; Desloover, J.; Fennell, D. E.; Rabaey, K. Electrochemically Driven Extraction and Recovery of Ammonia from Human Urine. Water Res. 2015, 87, 367-377.

(12) Lind, B. B.; Ban, Z.; Bydén, S. Nutrient Recovery from Human Urine by Struvite Crystallization with Ammonia Adsorption on Zeolite and Wollastonite. Bioresour. Technol. 2000, 73, 169-174.

(13) Ray, H.; Perreault, F.; Boyer, T. H. Ammonia Recovery from Hydrolyzed Human Urine by Forward Osmosis with Acidified Draw Solution. Environ. Sci. Technol. 2020, 54, 11556-11565. 
(14) Zamora, P.; Georgieva, T.; Ter Heijne, A.; Sleutels, T. H. J. A.; Jeremiasse, A. W.; Saakes, M.; Buisman, C. J. N.; Kuntke, P. Ammonia Recovery from Urine in a Scaled-up Microbial Electrolysis Cell. J. Power Sources 2017, 356, 491-499.

(15) Christiaens, M. E. R.; Gildemyn, S.; Matassa, S.; Ysebaert, T.; De Vrieze, J.; Rabaey, K. Electrochemical Ammonia Recovery from Source-Separated Urine for Microbial Protein Production. Environ. Sci. Technol. 2017, 51, 13143-13150.

(16) McCartney, S. N.; Williams, N. A.; Boo, C.; Chen, X.; Yip, N. Y. Novel Isothermal Membrane Distillation with Acidic Collector for Selective and Energy-Efficient Recovery of Ammonia from Urine. ACS Sustainable Chem. Eng. 2020, 8, 7324-7334.

(17) Tarpeh, W. A.; Barazesh, J. M.; Cath, T. Y.; Nelson, K. L. Electrochemical Stripping to Recover Nitrogen from SourceSeparated Urine. Environ. Sci. Technol. 2018, 52, 1453-1460.

(18) Christiaens, M. E. R.; Udert, K. M.; Arends, J. B. A.; Huysman, S.; Vanhaecke, L.; McAdam, E.; Rabaey, K. Membrane Stripping Enables Effective Electrochemical Ammonia Recovery from Urine While Retaining Microorganisms and Micropollutants. Water Res. 2019, 150, 349-357.

(19) Zhang, C.; Ma, J.; He, D.; Waite, T. D. Capacitive Membrane Stripping for Ammonia Recovery (CapAmm) from Dilute Wastewaters. Environ. Sci. Technol. Lett. 2018, 5, 43-49.

(20) Cerrillo, M.; Burgos, L.; Serrano-Finetti, E.; Riau, V.; Noguerol, J.; Bonmatí, A. Hydrophobic Membranes for Ammonia Recovery from Digestates in Microbial Electrolysis Cells: Assessment of Different Configurations. J. Environ. Chem. Eng. 2021, 9, No. 105289.

(21) Kuntke, P.; Rodríguez Arredondo, M.; Widyakristi, L.; Ter Heijne, A.; Sleutels, T. H. J. A.; Hamelers, H. V. M.; Buisman, C. J. N. Hydrogen Gas Recycling for Energy Efficient Ammonia Recovery in Electrochemical Systems. Environ. Sci. Technol. 2017, 51, 3110-3116.

(22) Rodrigues, M.; Paradkar, A.; Sleutels, T.; Heijne, A.; ter Buisman, C. J. N.; Hamelers, H. V. M.; Kuntke, P. Donnan Dialysis for Scaling Mitigation during Electrochemical Ammonium Recovery from Complex Wastewater. Water Res. 2021, 201, No. 117260.

(23) Lee, G.; Kim, D. Y.; Han, J. I. Gas-Diffusion-Electrode Based Direct Electro-Stripping System for Gaseous Ammonia Recovery from Livestock Wastewater. Water Res. 2021, 196, No. 117012.

(24) Kim, T.; Gorski, C. A.; Logan, B. E. Ammonium Removal from Domestic Wastewater Using Selective Battery Electrodes. Environ. Sci. Technol. Lett. 2018, 5, 578-583.

(25) Son, M.; Aronson, B. L.; Yang, W.; Gorski, C. A.; Logan, B. E. Recovery of Ammonium and Phosphate Using Battery Deionization in a Background Electrolyte. Environ. Sci. Water Res. Technol. 2020, 6, 1688-1696.

(26) Son, M.; Kolvek, E.; Kim, T.; Yang, W.; Vrouwenvelder, J. S.; Gorski, C. A.; Logan, B. E. Stepwise Ammonium Enrichment Using Selective Battery Electrodes. Environ. Sci. Water Res. Technol. 2020, 6, 1649-1657.

(27) Pronk, W.; Biebow, M.; Boller, M. Treatment of SourceSeparated Urine by a Combination of Bipolar Electrodialysis and a Gas Transfer Membrane. Water Sci. Technol. 2006, 53, 139-146.

(28) van Linden, N.; Bandinu, G. L.; Vermaas, D. A.; Spanjers, H.; van Lier, J. B. Bipolar Membrane Electrodialysis for Energetically Competitive Ammonium Removal and Dissolved Ammonia Production. J. Clean. Prod. 2020, 259, No. 120788.

(29) Rodrigues, M.; De Mattos, T. T.; Sleutels, T.; Ter Heijne, A.; Hamelers, H. V. M.; Buisman, C. J. N.; Kuntke, P. Minimal Bipolar Membrane Cell Configuration for Scaling up Ammonium Recovery. ACS Sustainable Chem. Eng. 2020, 8, 17359-17367.

(30) Chiao, Y. C.; Chlanda, F. P.; Mani, K. N. Bipolar Membranes for Purification of Acids and Bases. J. Membr. Sci. 1991, 61, 239-252.

(31) Mafé, S.; Ramírez, P.; Alcaraz, A. Electric Field-Assisted Proton Transfer and Water Dissociation at the Junction of a Fixed-Charge Bipolar Membrane. Chem. Phys. Lett 1998, 294, 406-412.

(32) Chen, M.; Zhang, F.; Zhang, Y.; Zeng, R. J. Alkali Production from Bipolar Membrane Electrodialysis Powered by Microbial Fuel Cell and Application for Biogas Upgrading. Appl. Energy 2013, 103, 428-434.
(33) Eisaman, M. D.; Parajuly, K.; Tuganov, A.; Eldershaw, C.; Chang, N.; Littau, K. A. CO2 Extraction from Seawater Using Bipolar Membrane Electrodialysis. Energy Environ. Sci. 2012, 5, 7346-7352.

(34) Gao, F.; Wang, L.; Wang, J.; Zhang, H.; Lin, S. Nutrient Recovery from Treated Wastewater by a Hybrid Electrochemical Sequence Integrating Bipolar Membrane Electrodialysis and Membrane Capacitive Deionization. Environ. Sci. Water Res. Technol. 2020, 6, 383-391.

(35) Klaassen, R.; Feron, P.; Jansen, A. Membrane Contactor Applications. Desalination 2008, 224, 81-87.

(36) Darestani, M.; Haigh, V.; Couperthwaite, S. J.; Millar, G. J.; Nghiem, L. D. Hollow Fibre Membrane Contactors for Ammonia Recovery: Current Status and Future Developments. J. Environ. Chem. Eng. 2017, 5, 1349-1359.

(37) Sürmeli, R. Ö.; Bayrakdar, A.; Çalli, B. Ammonia Recovery from Chicken Manure Digestate Using Polydimethylsiloxane Membrane Contactor. J. Clean. Prod. 2018, 191, 99-104.

(38) Mulder, M. Basic Principles of Membrane Technology, 2nd ed.; Springer Science \& Business Media, 2012.

(39) Lu, H.; Wang, L.; Wycisk, R.; Pintauro, P. N.; Lin, S. Quantifying the Kinetics-Energetics Performance Tradeoff in Bipolar Membrane Electrodialysis. J. Membr. Sci. 2020, 612, No. 118279.

(40) Yan, H.; Wu, L.; Wang, Y.; Shehzad, M. A.; Xu, T. Ammonia Capture by Water Splitting and Hollow Fiber Extraction. Chem. Eng. Sci. 2018, 192, 211-217.

(41) Yan, H.; Wu, L.; Wang, Y.; Irfan, M.; Jiang, C.; Xu, T. Ammonia Capture from Wastewater with a High Ammonia Nitrogen Concentration by Water Splitting and Hollow Fiber Extraction. Chem. Eng. Sci. 2020, 227, No. 115934.

(42) EPA. Method 350.2: Nitrogen, Ammonia (Colorimetric, Titrimetric, Potentiometric Distillation Procedure), 1974; pp 5-9.

(43) Strathmann, H. Ion-Exchange Membrane Separation Processes; Elsevier, 2004.

(44) Jaime-Ferrer, J. S.; Couallier, E.; Viers, P.; Rakib, M. TwoCompartment Bipolar Membrane Electrodialysis for Splitting of Sodium Formate into Formic Acid and Sodium Hydroxide: Modelling. J. Membr. Sci. 2009, 328, 75-80.

(45) Bard, A. J.; Faulkner, L. R. Electrochemical Methods: Fundamentals and Applications, 2nd ed.; 2001; Vol. 2.

(46) Vermaas, D. A.; Wiegman, S.; Nagaki, T.; Smith, W. A. Ion Transport Mechanisms in Bipolar Membranes for (Photo)Electrochemical Water Splitting. Sustainable Energy Fuels 2018, 2, 2006-2015.

(47) Givirovskiy, G.; Ruuskanen, V.; Ojala, L. S.; Lienemann, M.; Kokkonen, P.; Ahola, J. Electrode Material Studies and Cell Voltage Characteristics of the in Situ Water Electrolysis Performed in a PHNeutral Electrolyte in Bioelectrochemical Systems. Heliyon 2019, 5, No. e01690.

(48) Wang, L.; Lin, S. Intrinsic Tradeoff between Kinetic and Energetic Efficiencies in Membrane Capacitive Deionization. Water Res. 2018, 129, 394-401.

(49) Lin, S.; Elimelech, M. Kinetics and Energetics Trade-off in Reverse Osmosis Desalination with Different Configurations. Desalination 2017, 401, 42-52. 